Check for updates

Cite this: RSC Adv., 2019, 9, 21707

Received 25th April 2019

Accepted 5th July 2019

DOI: 10.1039/c9ra03099a

rsc.li/rsc-advances

\section{Secondary structure of end group functionalized oligomeric-L-lysines: investigations of solvent and structure dependent helicity $\dagger$}

\begin{abstract}
Merve Basak Canalp, ${ }^{a}$ Annette Meister ${ }^{\mathrm{b}}$ and Wolfgang $\mathrm{H}$. Binder (D) *a
Fibrillation of supramolecular building blocks represents an important model system for complex proteins and peptides, such as amyloidogenic proteins, displaying aggregation and subsequent collapse of their biological functions. In this work, we synthesized narrow-dispersed, end group-telechelic, oligomeric-( $($ lysine(carboxybenzyl (Z)/trifluoroacetyl (TFA)) $)_{n} \mathrm{~s}(n=3-33)$ as a model system for studying assembly and secondary structure formation, prepared via ring opening polymerization (ROP) of $N$-carboxyanhydrides (NCA). Our primary goal was to understand the influence of amino acid chain length and end groupmodification on the secondary structure and fibrillation of the oligo-Z/TFA-protected lysines. Synthesis was accomplished by initiation of ROP with 11-amino-undecene, followed by complete chain end functionalization reactions of the $\mathrm{N}$-terminus by 10 -undecenoyl-chloride. The so obtained oligomeric$(L-\text { lysine }(Z / T F A))_{n} S$ were fractionated according to their number of repeating units $(n)$ with preparative GPC using DMF as the eluent. As proven by MALDI-ToF MS, ${ }^{1} \mathrm{H}-\mathrm{NMR}$-spectroscopy and analytical GPC, they were separated into fractions with low polydispersity $(\Theta)$ values, ranging from $1.02-1.08$. Secondary structural investigations of these narrowly-dispersed oligomeric-(L-lysine(Z/TFA) ${ }_{n} \mathrm{~S}(n=33 \pm 6, n=18 \pm$ $6, n=12 \pm 4, n=5 \pm 2$ ) were accomplished by CD spectroscopy in TFE and HFIP, indicating that TFE was able to induce/stabilize the formation of $\alpha$-helicity. Fibril formation of oligomeric-(L-lysine $(Z / T F A))_{n} S$ with shorter chain lengths ( $n=7$ and $n=3$ ) were chosen to investigate the effect of the number of repeating units' role on the self-assembly of the oligomers in TFE. TEM images of these selected fractions, $f 19$ with $n=7$ and $\mathrm{f} 28$ with $n=3$, showed that fibrillization occured and the formation of a dense fibrillar mesh was observed when the amino acid chain length is equal to 7 . Therefore, the influences of the number of repeating units ( $n$ ), end-group functionalities (mono- or bis-functional) and the choice of solvents (TFE or HFIP) on the propensity to form helical structure allowed us to calibrate their secondary structure.
\end{abstract}

\section{Introduction}

Homopolymers and copolymers of amino acids, ${ }^{1}$ which are able to adopt the main secondary structural features such as alpha helices and beta sheets, hold importance for understanding the formation of the $3 \mathrm{D}$ structures of proteins. ${ }^{2}$ Not only protein folding, but more importantly protein and peptide assemblies ${ }^{3}$ are within the spotlight of interest ${ }^{4}$ of researchers, who seek to shed light on the pathogenesis of neurodegenerative disorders such as, e.g., in Alzheimer's and Parkinson's diseases. ${ }^{5-7}$ Quite a range of different peptides have been reported to form fibrils

${ }^{a}$ Faculty of Natural Science II (Chemistry, Physics and Mathematics), Martin Luther University Halle-Wittenberg, von-Danckelmann-Platz 4, Halle (Saale) D-06120, Germany. E-mail: wolfgang.binder@chemie.uni-halle.de

${ }^{b}$ Institute of Biochemistry and Biotechnology, Martin Luther University HalleWittenberg, Kurt-Mothes-Straße 3a, Halle (Saale) D-06120, Germany

$\dagger$ Electronic supplementary information (ESI) available. See DOI: 10.1039/c9ra03099a via mechanisms not largely dissimilar to those of amyloid-beta 1-42 peptide $\left(\mathrm{A} \beta_{42}\right){ }^{8}$ Especially amphiphilic peptide-conjugates, ${ }^{9}$ that are prone to aggregation, display fibrillation via nucleation dependent aggregation mechanisms. Poly-L-lysine (PLL) in particular has received significant attention in the field of biomedicine, ${ }^{\mathbf{1 0 - 1 6}}$ as it possesses inter- and intra-molecular folding behaviour, where its subsequent assembly can lead to complex, often even fibrillar-like structures. Thus, dynamic conformational changes of PLL depends on various external chemical and physical conditions having been studied both in solution and in the solid state, with an unclear contribution of end groups and chain length. ${ }^{17,18}$ In solution, high molecular weight $\operatorname{PLL}(Z)(n>5000)$ has shown transitions from helical conformations to random coil in $35-40 \%$ of dichloroacetic acid/ chloroform mixture as measured by its optical rotatory dispersion. ${ }^{19}$ Secondary structural changes of $\mathrm{PLL} \cdot \mathrm{HCl}(n=200)$ have been analysed by $\mathrm{CD}$ spectroscopy, indicating a random coil at low $\mathrm{pH}$, an $\alpha$-helix at a $\mathrm{pH}>10.6$ and a $\beta$-sheet at $60{ }^{\circ} \mathrm{C} .{ }^{20}$ There has been a pronounced solvent-influence on the conformation 
of PLL-oligomers, stimulating investigations on the conformational distributions of $\mathrm{PLL} \cdot \mathrm{HCl}(31 \mathrm{kDa})$ by IR spectroscopy in $\mathrm{D}_{2} \mathrm{O}$, DMSO, TFE and ethylene glycol. Mirtič et al. have suggested that an increase in temperature $\left(T=80^{\circ} \mathrm{C}\right)$ induced the formation of $\beta$ structures, while TFE and DMSO stabilized $\alpha$ helices. ${ }^{21}$ Solid state investigations of PLL(Z) films (DP: 18), cast from DMF as a solvent, reveal a $3.6 \mathrm{~nm} \alpha$-helix (5 turns) within a simple hexagonal unit cell. ${ }^{18}$ Huesmann et al. ${ }^{22}$ have investigated poly-L-lysine(Z)s with $n=24,57,87,196$ and $\emptyset_{\mathrm{s}}$ around 1.70 as well as poly-L-lysine(TFA)s $(n=20,65,90,143)$ with $\bigoplus_{\mathrm{s}}$ up to 1.95 via $\mathrm{CD}$, showing an increase in helicity with increasing number of repeating units $(n)$ for poly-L-lysine(Z)s in 1,1,1,3,3,3hexafluoroisopropanol (HFIP). In these investigations, poly-Llysine(Z) with $n=5-15$ did not display an ordered secondary conformation as proven via $\mathrm{CD}$, whereas with a chain length of $n \approx 60 \alpha$-helicity was observed in HFIP.

Our study aims to investigate the secondary structural behaviour of: (i) the chain end effects introduced by C11 alkyl groups on each end of the peptide, similar to lipid/peptide hybrids in e.g. lipopeptides ${ }^{23}$ or peptide amphiphiles ${ }^{24,25}$ and (ii) investigate the influence of the side chain effects of the protecting groups, $\mathrm{Z}(\mathrm{Cbz})$ and TFA, exerted on the oligomeric lysines in solution. In order to get a deeper understanding of the effects of the number of repeating units $(n)$ on the formation of helices and their fibrillation behaviour, we have fractionated the $\mathrm{N}$-terminus functionalized oligomers, enabling us to perform investigations by CD in two different solvents (HFIP and TFE) with the aim to understand to what extent TFE can stabilize $\alpha$-helix formation. We therefore have prepared oligomeric L-lysines with low molecular weights $\left(M_{\mathrm{n}}=2-3 \mathrm{kDa}\right)$ via ROP of NCA monomers using 11-aminoundecene as the primary amine initiator, followed by an additional chain end functionalization via amidation reaction of the amino group of the N-terminus with 10-undecenoyl chloride. Subsequently, fractionated samples of $\mathrm{N}$-terminus functionalized oligomers obtained by preparative GPC were investigated by MALDI-ToF MS, analytical GPC and CD spectroscopy to study their conformational behaviour at precise chain lengths $(n)$.

\section{Experimental section}

\section{Materials and methods}

DMF was dried over $\mathrm{CaH}_{2}$ and freshly distilled by applying vacuum $(20 \mathrm{mbar})$ at $50{ }^{\circ} \mathrm{C}$. Ethyl acetate was dried at $100{ }^{\circ} \mathrm{C}$ with $\mathrm{P}_{2} \mathrm{O}_{5} . \mathrm{N}$-heptane was refluxed over sodium/benzophenone at $120{ }^{\circ} \mathrm{C}$. All of the dried solvents were flushed with $\mathrm{N}_{2}$ gas before usage. All of the reagents were purchased from Sigma-Aldrich. All NMR-spectra were recorded on a Varian spectrometer (Gemini 200, Gemini 2000 and Unity 500) at 400 or $500 \mathrm{MHz}$ at $27^{\circ} \mathrm{C}$. Trimethylsilane was used as internal standard. Deuterated chloroform $\left(\mathrm{CDCl}_{3}\right)$ and dimethyl sulfoxide (DMSO- $\left.\mathrm{d}_{6}\right)$ were used as solvent. In the case of all polymer samples trifluoroacetic acid (TFA) (15\% of volume) was added to the deuterated chloroform $\left(\mathrm{CDCl}_{3}\right)$. All chemical shifts $(\delta)$ were reported in parts per million (ppm) and the coupling constant $(J)$ in Hertz. For the interpretation of the spectra MestReNova v. 6.0.2 5475 was used. For analytical GPC measurements a Viscotek GPCmax VE 2001 with an HHR-H Guard-17369 and a GMHHR-N-18055 column in DMF at $60^{\circ} \mathrm{C}$ was used. The sample concentration was $5 \mathrm{mg} \mathrm{mL}^{-1}$, the injection volume was $100 \mu \mathrm{L}$. The detection was carried out via the refractive index with a VE 3580 RI detector of Viscotek at a temperature of $35^{\circ} \mathrm{C}$ and a flow rate of $1 \mathrm{~mL} \mathrm{~min}{ }^{-1}$. Polystyrene standards with molecular weights from 1000, $\mathrm{g} \mathrm{mol} \mathrm{mo}^{-1}$ to $115000 \mathrm{~g} \mathrm{~mol}^{-1}$ were used for external calibration. Preparative GPC was performed by a KD-2002.5 column from Shodex company attached on a VWR HITACHI Chromaster instrument using DMF (HPLC graded) as the eluent at $55{ }^{\circ} \mathrm{C}$ with a flow rate of $0.70 \mathrm{~mL} \mathrm{~min}^{-1}$ injecting sample with the concentration of $15 \mathrm{mg} \mathrm{mL}{ }^{-1}$ where refractive index detector from VWR at $50{ }^{\circ} \mathrm{C}$ was employed as the detector. The obtained data were analysed by using EZChrom Elite (version 3.3.2 SP2) software. ESI-ToF measurements were performed on a Focus micro ToF by Bruker Daltonics. The sample $(1.00 \mathrm{mg})$ was dissolved in methanol (1.00 mL, HPLC grade) and directly infused $\left(180.00 \mu \mathrm{L} \mathrm{h}^{-1}\right.$, positive or negative mode). MALDI-TOF MS measurements were carried out in reflector mode on a Bruker Autoflex III Smart beam equipped with a nitrogen laser source $(\lambda=337 \mathrm{~nm})$. The samples were dissolved in DMF (HPLC grade) $\left(c=10 \mathrm{mg} \mathrm{mL}^{-1}\right)$ with a ratio of $100: 10: 1$ (matrix : analyte $:$ salt). The matrix dithranol with $c=10 \mathrm{mg} \mathrm{mL}^{-1}$ in THF, the salt potassium trifluoroacetate (KTFA) with $c=5 \mathrm{mg} \mathrm{mL}^{-1}$ in THF were used. For the data evaluations and simulation of the mass spectra of the polymer samples the computer programme Flex analysis (version 3.0) was used. CD spectroscopy measurements were performed with the instrument, JASCO Corp., J-810, Rev. 1.00, at a constant temperature $\left(20^{\circ} \mathrm{C}\right)$. The $\mathrm{UV}$ absorption was measured in CD units of millidegrees in the wavelength range of 260-190 $\mathrm{nm}$. The cuvette cell used had a diameter of $0.1 \mathrm{~cm}$. The correction of the measurements was done by subtraction of the absorption of the pure solvents e.g. 1,1,1,3,3,3-hexafluoroisopropanol (HFIP) and 2,2,2-trifluoroethanol (TFE) from the absorbance of the sample. The negatively stained samples for Transmission Electron Microscopy (TEM) were prepared by spreading $5 \mu \mathrm{L}$ of the dispersion $\left(0.2 \mathrm{mg} \mathrm{mL}^{-1}\right.$ in TFE) onto a $\mathrm{Cu}$ grid coated with a Carbon-film (PLANO, Wetzlar, D). After 1 min excess liquid was blotted off with filter paper and $5 \mu \mathrm{L}$ of $1 \%$ aqueous uranyl acetate solution were placed onto the grid and drained off after 1 min. The dried specimens were examined with an EM 900 transmission electron microscope (Carl Zeiss Microscopy GmbH, Oberkochen, Germany). Micrographs were taken with a SSCCD SM-1k-120 camera (TRS, Moorenweis, Germany).

\section{Synthesis of $\mathrm{N}$-carboxyanhydride (NCA) monomers}

Synthesis of $\boldsymbol{N}$-carboxyanhydride of $\boldsymbol{N}$-carboxybenzyl-t-lysine, $\operatorname{NCA}(Z)$. The reaction of NCA of $N$-carboxybenzyl-L-lysine has been reported in the literature ${ }^{26}$ (see $\mathrm{ESI}^{\dagger}$ ).

Synthesis of $\mathrm{N}$-carboxyanhydride of $\mathrm{N}$-trifluoroacetyl-Llysine, NCA(TFA). The synthesis of NCA(TFA) was performed in the same way as $\mathbf{N C A}(\mathrm{Z})$ (see $\mathrm{ESI}_{\dagger} \dagger$ ).

\section{Ring opening polymerization (ROP) of NCA monomers}

ROP of NCA of $N$-carboxybenzyl-L-lysine, O-K(Z). O-K(Z) was performed similar to the procedure with small modifications. ${ }^{27}$ In 
a dry Schlenk flask equipped with a small magnetic stir bar, the pre-dried monomer NCA(Z) (473 mg, $1.55 \mathrm{mmol}$ ) was dissolved in dry DMF. Subsequently, 11-amino-undecene (54 mg, $0.31 \mathrm{mmol}$ ) in $1 \mathrm{~mL}$ of dry DMF was added into the reaction mixture via syringe under nitrogen atmosphere. The Schlenk flask connected to the Schlenk line was evacuated from 750 mbar to 40 mbar. The reaction mixture was allowed to stir at room temperature under vacuum for two days. The polymer was precipitated into $50 \mathrm{~mL}$ of diethyl ether and washed with diethyl ether for several times. The polymer, OK(Z) was dried under high vacuum and kept in a vial at room temperature. ${ }^{1} \mathrm{H}-\mathrm{NMR}\left(\mathrm{CDCl}_{3}, 15 \%\right.$ vol TFA, $\left.500 \mathrm{MHz}\right)$ $\delta$ (ppm): 7.94-7.29 (m, 59H, aryl- $H$ ), 5.82 (ddt, $1 \mathrm{H}, \mathrm{CH}_{2} \mathrm{C}=\mathrm{CH}-$ $\left.\mathrm{CH}_{2},{ }^{3,3,3} J_{\mathrm{H}, \mathrm{H}}=13.5,10.3,6.7 \mathrm{~Hz}\right), 5.26-4.78\left(\mathrm{~m}, 25 \mathrm{H}, \mathrm{CH}_{2} \mathrm{C}=\mathrm{C}\right.$, $\left.\mathrm{CH}_{2}\right), 4.42\left(\mathrm{~d}, 9 \mathrm{H}, \mathrm{CH},{ }^{3} \mathrm{~J}_{\mathrm{H}, \mathrm{H}}=6.7 \mathrm{~Hz}\right), 3.39-2.99\left(\mathrm{~m}, 25 \mathrm{H}, \mathrm{CH}_{2}\right)$, 2.30-1.15 (m, 94H, $\mathrm{CH}_{2}$ ). MS (MALDI-ToF, Dithranol/KTFA): $\mathrm{m} / \mathrm{z}$ calc. $=1518.8[\mathrm{M}+\mathrm{K}]^{+}, m / z$ exp. $=1519.0[\mathrm{M}+\mathrm{K}]^{+}$.

ROP of NCA of $\boldsymbol{N}$-trifluoroacetyl-L-lysine, O-K(TFA). The synthesis of ROP of NCA(TFA) was performed similar to the ROP of NCA(Z). ${ }^{1} \mathrm{H}-\mathrm{NMR}\left(\mathrm{CDCl}_{3}, 15 \%\right.$ vol TFA, $\left.400 \mathrm{MHz}\right) \delta(\mathrm{ppm})$ : $5.80\left(\mathrm{dd}, 1 \mathrm{H}, \mathrm{CH}_{2}=\mathrm{CH}-,{ }^{3,3} J_{\mathrm{H}, \mathrm{H}}=16.6,6.6 \mathrm{~Hz}\right), 4.95(\mathrm{dd}, 2 \mathrm{H}$, $\left.\mathrm{CH}_{2}=\mathrm{CH}-,{ }^{2,3} J_{\mathrm{H}, \mathrm{H}}=30.2,13.6 \mathrm{~Hz}\right), 4.79\left(\mathrm{dd}, 1 \mathrm{H}, \mathrm{CH},{ }^{3,3} J_{\mathrm{H}, \mathrm{H}}=\right.$ 9.9, $5.4 \mathrm{~Hz}), 4.40(\mathrm{~m}, 4 \mathrm{H}, \mathrm{CH}), 3.43\left(\mathrm{~d}, 18 \mathrm{H}, \mathrm{CH}_{2},{ }^{3} J_{\mathrm{H}, \mathrm{H}}=6.6 \mathrm{~Hz}\right)$, 2.14-1.15 (m, 51H, CH $\mathrm{C}_{2}$. MS (MALDI-ToF, Dithranol/KTFA): $\mathrm{m} / z$ calc. $=1328.5[\mathrm{M}+\mathrm{K}]^{+}, m / z$ exp. $=1328.6[\mathrm{M}+\mathrm{K}]^{+}$.

\section{N-terminus functionalization of oligomers}

$\mathbf{N}$-terminus functionalization of oligo-carboxybenzyl-Llysine, $\mathbf{N - O K}(\mathrm{Z})$. In a sealed glass vial equipped with a small magnetic stir bar, OK(Z) (150 mg, 1 eq.) was added and dissolved in $1.50 \mathrm{~mL}$ dry DMF and allowed to stir under nitrogen atmosphere. Subsequently, 10-undecenoyl-chloride (103 mg, $0.85 \mathrm{~mL}$ in DCM, 5 eq.) and $\mathrm{Et}_{3} \mathrm{~N}$ ( $56 \mathrm{mg}, 0.08 \mathrm{~mL}, 5$ eq.) was added to the mixture via a syringe. The reaction mixture was stirred at room temperature over-night under nitrogen. The product was precipitated into cold diethyl ether and was washed with diethyl ether several times. $\mathbf{N}-\mathbf{O K}(\mathbf{Z})$ was dried under high vacuum and kept in a vial at room temperature. ${ }^{1} \mathrm{H}-\mathrm{NMR}\left(\mathrm{CDCl}_{3}, 15 \%\right.$ vol TFA $500 \mathrm{MHz}) \delta(\mathrm{ppm}): 8.21-7.30(\mathrm{~m}, 223 \mathrm{H}$, aryl $H), 5.80(\mathrm{dd}, 2 \mathrm{H}$, $\left.\mathrm{CH}_{2}=\mathrm{CH}-,{ }^{3,3} J_{\mathrm{H}, \mathrm{H}}=10.2,6.8 \mathrm{~Hz}\right), 5.32-4.84\left(\mathrm{~m}, 74 \mathrm{H}, \mathrm{H}_{2} \mathrm{C}=\mathrm{C}\right.$, $\left.\mathrm{CH}_{2}\right), 4.43(s, 7 \mathrm{H}, \mathrm{CH}), 3.24\left(\mathrm{~d}, 2 \mathrm{H}, \mathrm{CH}_{2},{ }^{3} J_{\mathrm{H}, \mathrm{H}}=5.9 \mathrm{~Hz}\right), 2.48-1.05$ (m, 340H, $\mathrm{CH}_{2}$ ). MS (MALDI-ToF, Dithranol/KTFA): $\mathrm{m} / \mathrm{z}$ calc. $=$ $1669.0[\mathrm{M}+\mathrm{K}]^{+}, m / z$ exp. $=1668.5[\mathrm{M}+\mathrm{K}]^{+}$.

$\mathrm{N}$-terminus functionalization of oligo-trifluoroacetyl-Llysine, N-OK(TFA). The N-terminus functionalization of $\mathbf{O}$ K(TFA) was performed in the same way as $\mathbf{N - O K}(\mathbf{Z})$ synthesis. ${ }^{1} \mathrm{H}-\mathrm{NMR}\left(\mathrm{CDCl}_{3}, 15 \%\right.$ vol TFA $\left.500 \mathrm{MHz}\right) \delta(\mathrm{ppm}): 5.80(\mathrm{dd}, 2 \mathrm{H}$, $\left.\mathrm{CH}_{2}=\mathrm{CH}-,{ }^{3,3} J_{\mathrm{H}, \mathrm{H}}=10.2,6.8 \mathrm{~Hz}\right), 4.95\left(\mathrm{dd}, \mathrm{H}_{2} \mathrm{C}=\mathrm{C}, \mathrm{CH}_{2}\right), 4.43$ $(s, 7 \mathrm{H}, \mathrm{CH}), 3.24\left(\mathrm{~d}, 2 \mathrm{H}, \mathrm{Hd}, \mathrm{i}, \mathrm{CH}_{2},{ }^{3} J_{\mathrm{H}, \mathrm{H}}=5.9 \mathrm{~Hz}\right), 2.48-1.05(\mathrm{~m}$, $340 \mathrm{H}, \mathrm{CH}_{2}$ ). MS (MALDI-ToF, Dithranol/KTFA): $\mathrm{m} / \mathrm{z}$ calc. $=$ $1494.7[\mathrm{M}+\mathrm{K}]^{+}, m / z$ exp. $=1494.7[\mathrm{M}+\mathrm{K}]^{+}$.

\section{Results and discussion}

The synthesis of defined oligo-/poly-L-lysines is conventionally accomplished by ring opening polymerization of $\mathrm{N}$-carboxyanhydrides (NCA) ${ }^{28,29}$ bearing either carboxybenzyl (Cbz, Z)-L-lysine (NCA(Cbz, Z)) or the trifluoroacetyl (TFA)-L-lysine (NCA(TFA)), initiated by primary and secondary amines such as hexylamine or diethylamine in DMF. ${ }^{22,30-33}$ As livingness and end group fidelity during ROP of NCAs can be achieved via the "Normal Amine Mechanism (NAM)" using primary or secondary amines as initiators, ${ }^{34,35}$ we have polymerized the two NCA-monomers of carboxybenzyl-t-lysine, NCA(Z), and trifluoroacetyl-t-lysine, NCA(TFA) via the primary amine, 11-aminoundecene to obtain the monofunctionalized oligomers $\mathbf{O K}(\mathbf{Z})$ and $\mathbf{O K}(\mathbf{T F A})$ in the first step. Subsequently, we have functionalized the N-terminus end groups of the oligomers OK(Z) and OK(TFA) by direct amidation with 10undecenoyl chloride in situ to achieve the respective bisfunctionalized oligomers N-OK(Z) and N-OK(TFA) (see Scheme 1). Subsequently, the bis-functionalized oligomers $\mathbf{N}-\mathbf{O K}(\mathbf{Z})$ and $\mathbf{N}$ -
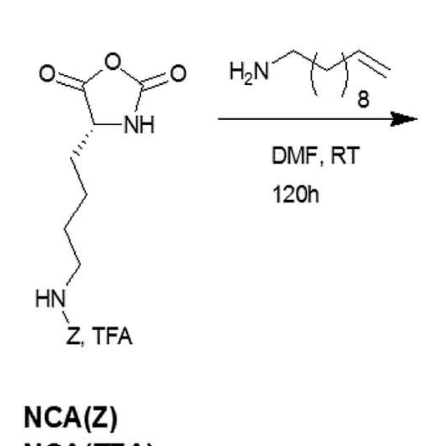

NCA(TFA)

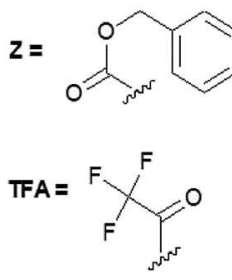

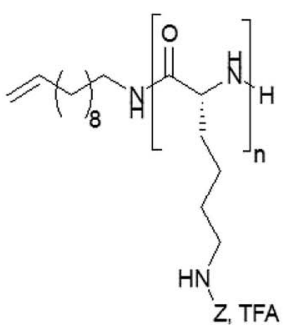

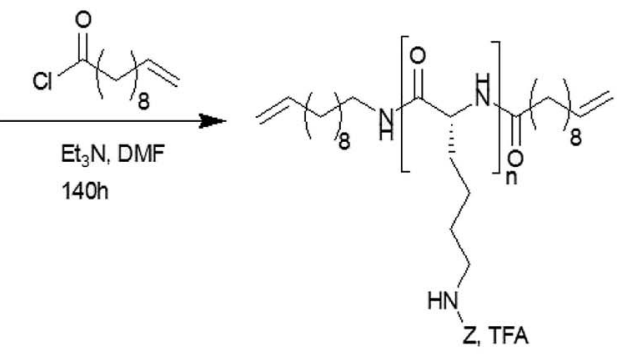

$\mathrm{OK}(\mathrm{Z})$

OK(TFA)
$\mathrm{N}-\mathrm{OK}(\mathrm{Z})$

N-OK(TFA)

Scheme 1 Synthetic pathway of mono- and bis-functionalized oligo-L-lysines. 
OK(TFA) were fractionated by preparative GPC and then investigated by MALDI-ToF MS, analytical GPC, ${ }^{1} \mathrm{H}-\mathrm{NMR}$ and CD spectroscopy.

\section{Fractionation by preparative GPC}

The bis-functionalized oligo-L-lysines N-OK(Z) and N-OK(TFA) were separated into fractions according to their molecular weights (the number of repeating units $(n)$ ) displaying lower polydispersity $(\nexists)$ values, obtained via preparative GPC in DMF as the eluent at a column temperature of $55^{\circ} \mathrm{C}$.

As presented in Fig. 1 and 2, both N-OK(Z) and N-OK(TFA) were fractionated successfully, see Fig. 1A and B, collecting the different fractions, labelled as $\mathrm{f} x$. As can be seen from Fig. 1A, for $\mathbf{N}-\mathbf{O K}(\mathrm{Z}) 11$ fractions (f) f12-f28 were collected, whereas the fractionation of N-OK(TFA) resulted only in 4 fractions which were referred to as $\mathrm{f} 2(n=6), \mathrm{f} 3(n=5), \mathrm{f} 4(n=4)$ and $\mathrm{f} 5(n=3)$ (Fig. 1B). After fractionation, all fractions were analysed by analytical GPC as shown in Fig. 1C (for N-OK(Z)) and Fig. 1D (for N-OK(TFA)), displaying significantly narrow polydispersity values as compared to the unfractionated samples, $\mathbf{N - O K}(\mathbf{Z})$ and N-OK(TFA). Subsequently, all selected fractions were also analysed by MALDI-ToF MS (see Fig. 2 and Table 1) as well as ${ }^{1} \mathrm{H}$ NMR spectroscopy (see Fig. 3).

In Fig. 2, the MALDI spectra of both fractionated oligomers f28, f19, f15, f14, f12 of N-OK(Z) (b-f) and f5, f4, f3, f2 of NOK(TFA) (h-k) along with the oligomers (a and $g$ ) before

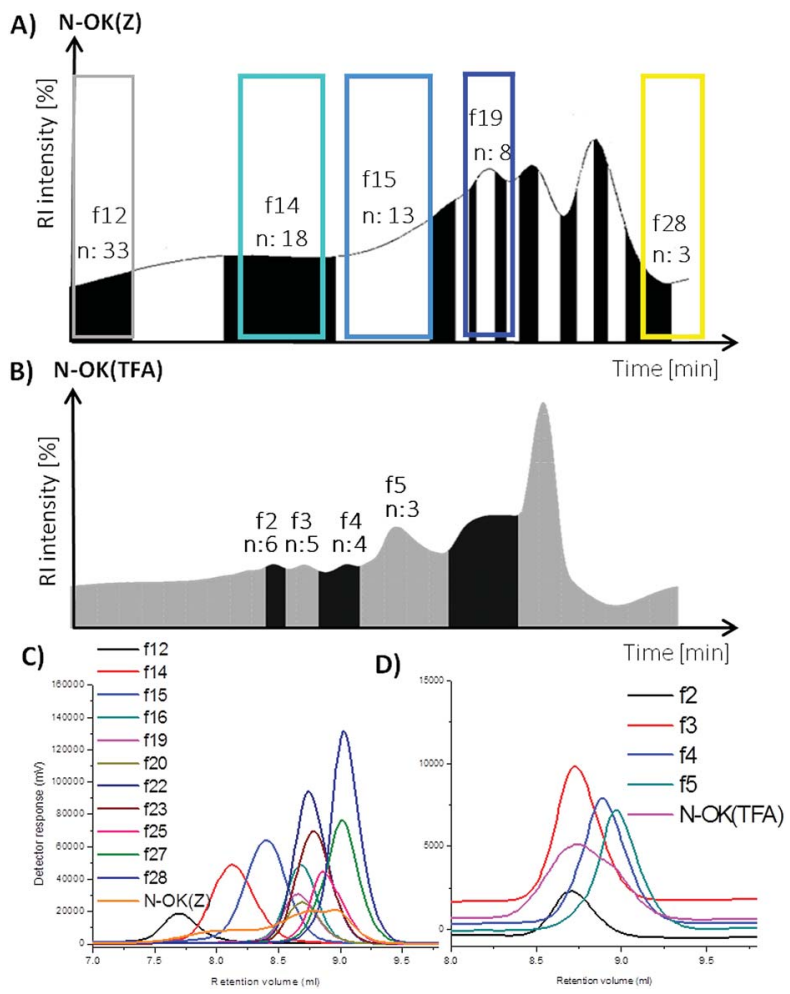

Fig. 1 Preparative GPC graphs of (A) N-OK(Z), (B) N-OK(TFA) and analytical GPC graphs of (C) N-OK(Z), (D) N-OK(TFA) along with the selected fractions.

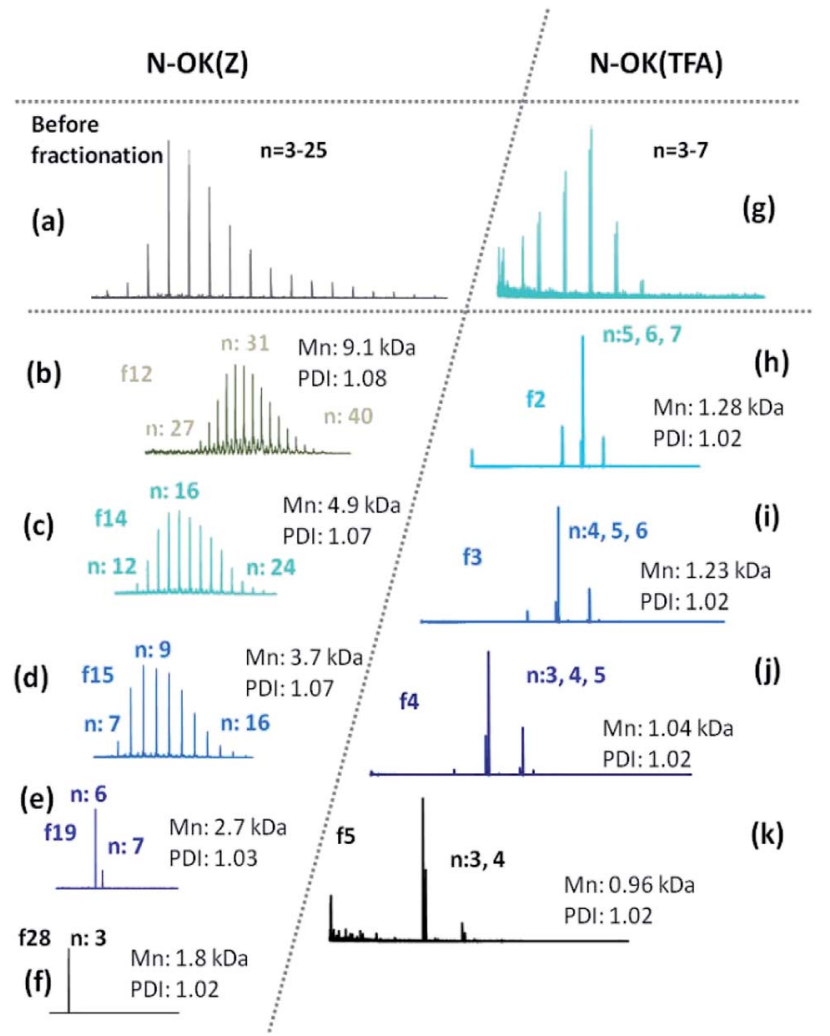

Fig. 2 MALDI-TOF MS of (a) N-OK(Z), (b-f) fractions of N-OK(Z), (g) N$\mathrm{OK}(\mathrm{TFA})$ and $(\mathrm{h}-\mathrm{k})$ fractions of $\mathrm{N}-\mathrm{OK}(\mathrm{TFA})$

fractionation are shown. MALDI spectra prove that the fractions were well separated, with defined end group functionalities on both sides of the respective oligomers, as shown by the excellent match between the simulated and the measured isotopic patterns of the samples (see details in the ESI, Fig. 19S-29S and $31 \mathrm{~S}-33 \mathrm{~S} \dagger$ ). The analytical GPC results also support (see Fig. 2 and Table 1 ) the very narrow $D$ values for each fraction with small variations in the numbers of repeating units $(n)$. Thus, at $n=3$ to 8 only a chain variation of \pm 2 was obtained, and at $n=$ 12-33 the variation was \pm 6 .

As shown in Fig. 3, we have investigated the fractions f12 and f28 of N-OK(Z) by ${ }^{1} \mathrm{H}-\mathrm{NMR}$ spectroscopy in $\mathrm{CDCl}_{3}$ (15\% volume TFA added), proving their chemical identity and a good match to the data obtained by GPC and MALDI.

All analytical data of the samples are summarized in Table 1, along with the respective $n, M_{\mathrm{n}}$ and $\emptyset$ values.

\section{Secondary structural analyses by CD spectroscopy}

Circular dichroism (CD) is an excellent tool for the rapid determination of the secondary structure and folding properties of proteins. ${ }^{36}$ In this work, the analysis of the secondary structures of the oligomers was conducted in 1,1,1,3,3,3-hexafluoroisopropanol (HFIP) and 2,2,2-trifluoroethanol (TFE). We chose HFIP and TFE as solvents, as they both act as the good solvents $^{24}$ for our side chain protected oligomers for the CD measurements. The measured CD spectroscopy data were reported as ellipticity $(\theta)$ [mdeg]. The percentage values of $\alpha$-helicity of the samples were calculated according to the eqn (1), 
Table 1 Summary of all the molecular weight data, as well as the CD analyses of all unfractionated and fractionated oligomers

\begin{tabular}{lllllll}
\hline Entry & Sample & $n_{\text {(MALDI) }}$ & $M_{\text {n(MALDI) }}$ & $M_{\mathrm{n} \text { (GPC) }}$ & $D$ & CD-spec. (HFIP) \\
\hline I & OK(Z) & $15 \pm 10$ & 4.1 & 2.5 & 1.36 & $22 \% \alpha$-helicity \\
II & N-OK(Z) & $15 \pm 10$ & 4.2 & 1.4 & 1.36 & $16 \% \alpha$-helicity \\
III & N-OK(Z)-2 & $8 \pm 2$ & 2.1 & 1.9 & 1.02 & $\beta$ II turn \\
IV & N-OK(Z)-3 & $24 \pm 8$ & 5.6 & 8.0 & 1.33 & $40 \% \alpha$-helicity \\
V & f12 & $33 \pm 6$ & 8.9 & 9.1 & 1.08 & $19 \% \alpha$-helicity \\
VI & f14 & $18 \pm 6$ & 4.9 & 4.9 & 1.07 & $15 \% \alpha$-helicity \\
VII & f15 & $12 \pm 4$ & 3.4 & 3.7 & 1.07 & $\beta$ II turn \\
VIII & f16 & $8 \pm 2$ & 2.3 & 2.6 & 1.02 & $\beta$ II turn \\
IX & f19 & $6 \& 7$ & 2.1 & 2.6 & 1.03 & $\beta$ II turn \\
X & f20 & $6 \pm 2$ & 2.1 & 2.6 & 1.03 & $\beta$ II turn \\
XI & f23 & $5 \pm 1$ & 1.8 & 2.3 & 1.03 & $\beta$ II turn \\
XII & f25 & $4 \pm 1$ & 1.5 & 2.0 & 1.03 & $\beta$ II turn \\
XIII & f28 & 3 & 1.1 & 1.8 & 1.02 & $\beta$ II turn \\
XIV & OK(TFA) & $6 \pm 3$ & 1.5 & 1.0 & 1.09 & $16 \% \alpha$-helicity \\
XV & N-OK(TFA) & $6 \pm 3$ & 1.6 & 1.2 & 1.05 & $\beta$ II turn \\
XVI & f2 & $6 \pm 1$ & 1.4 & 1.3 & 1.02 & $\beta$ II turn \\
XVII & f3 & $5 \pm 1$ & 1.2 & 1.2 & 1.02 & $\beta$ II turn \\
XVIII & f4 & $4 \pm 1$ & 1.0 & 1.0 & 1.02 & $\beta$ II turn \\
XIX & f5 & $3 \& 4$ & 0.90 & 0.96 & 1.02 & $\beta$ II turn
\end{tabular}

used for the estimation of the helicity of the peptide chains by Krannig and Sun et al.: ${ }^{37}$

$$
\alpha \text {-helix }(\%)=\left(-[\theta]_{222}+3000\right) / 39000 \times 100 \%
$$

The summary of all CD spectroscopy measurements along with analytical GPC results of oligomers and their fractions are presented in Table 1. The secondary structural investigations of the fractions of N-OK(Z); f28, f19, f15, f14, f12 and of N-OK(TFA); $\mathrm{f} 4, \mathrm{f} 3, \mathrm{f} 2$ in TFE are depicted in Fig. $4 \mathrm{~A}$ and $\mathrm{B}$ respectively (also see Table 1).

Firstly, we investigated the effect of the number of repeating units $(n)$ on formation of secondary structures by CD spectroscopy, aiming to understand changes in $\alpha$-helicity with increasing chain length $n$ of the bis-substituted N-OK(Z) oligomers (Fig. 4A and Table 1, entries V-XIII). In Fig. 4A, one can see

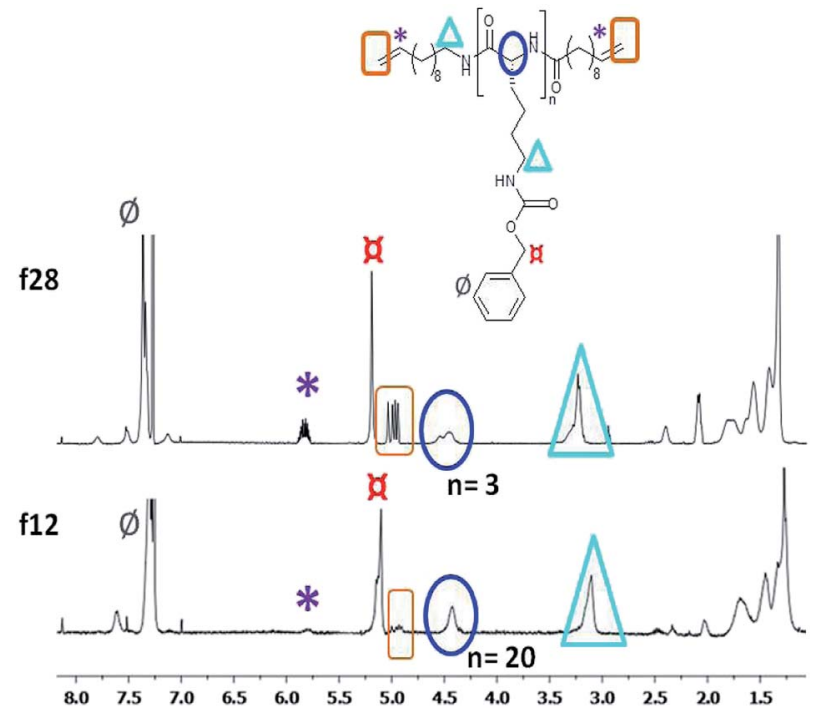

Fig. $3{ }^{1} \mathrm{H}-\mathrm{NMR}$ spectra of fractions of $\mathrm{N}-\mathrm{OK}(\mathrm{Z}), \mathrm{f} 28$ and $\mathrm{f} 12$ measured in $\mathrm{CDCl}_{3}$ (15 vol\% TFA). an increase in $\alpha$-helicity of the oligomers with increasing $n$ via enhancement of the $[\theta]_{222}$ signal of the fractions of $\mathbf{N}-\mathbf{O K}(\mathbf{Z}) \mathbf{f 1 2}$, f14, f15, f19 and f28 (Table 1, entries V-VII, IX, XIII) in TFE. Because of their low number of repeating units $(n=3-7)$, fractions of N-OK(TFA) f2, f3, f4 (Table 1, entries XVI-XIX) do not display helicity for $\mathrm{f} 4$, with only $19 \%$ helicity for $\mathrm{f} 2$. Therefore, as shown in Fig. 5 , chain length dependence of $\alpha$-helicity in TFE is demonstrated for the bis-functional fractionated samples with the Z-group protected moieties possessing low $Ð$ values $(<1.07)$, e.g. fractions of $\mathrm{N}-\mathrm{OK}(\mathrm{Z})$ : $\mathrm{f} 28$, f19, $\mathrm{f} 15, \mathrm{f} 14, \mathrm{f} 12)$, indicating an almost linear increase in $\alpha$-helicity (from $12 \%$ up to $33 \%$ ) with increasing number of repeating units $(n)$. It should be noted that this trend is also visible in the unfractionated samples: thus the unfractionated bis-functional oligomer $\mathbf{N}$ OK(Z)-2, $(n=8)$ (Table 1 , entry III) displays a lower $\alpha$-helicity

A)

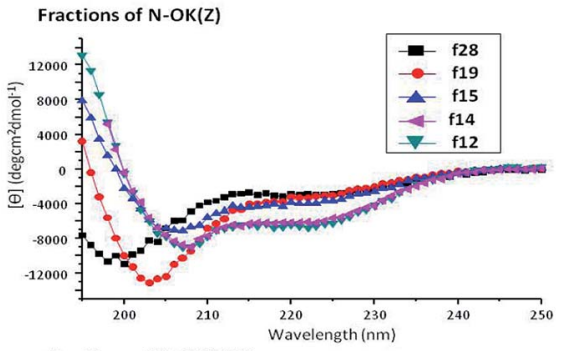

B)

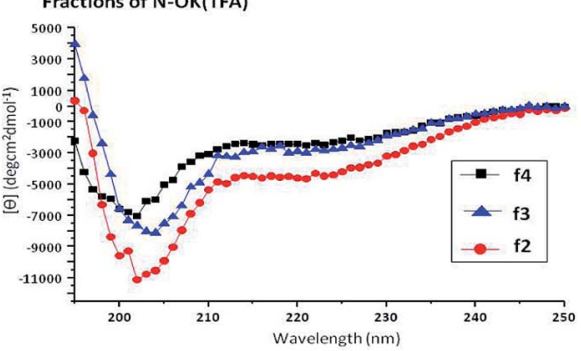

Fig. 4 CD spectra of the fractions of (A) N-OK(Z) and (B) N-OK(TFA) in TFE ( $c=0.2 \mathrm{mg} \mathrm{mL}^{-1}$ ). 


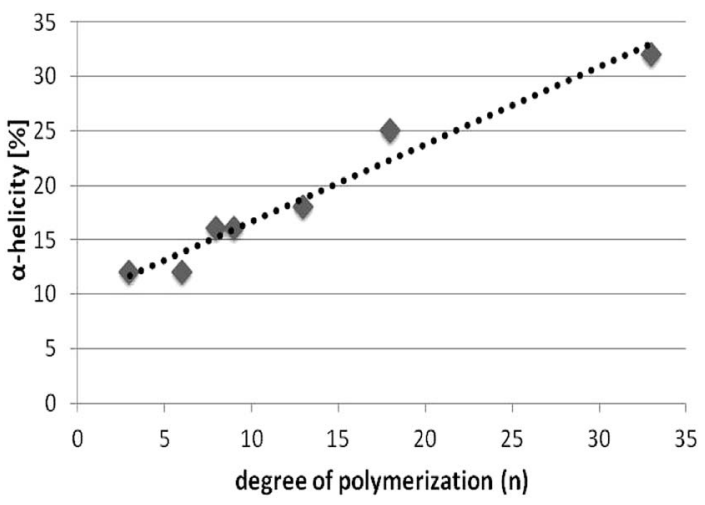

Fig. 5 Depiction of increase in $\alpha$-helicity [\%] with respect to increasing number of repeating units $(n)$ of fractions of $\mathrm{N}-\mathrm{OK}(\mathrm{Z})$ in TFE (line is a guide for the eye only).

(18\% in TFE) compared to the unfractionated bis-functional oligomer N-OK(Z)-3, $(n=24)$ (53\% in TFE, $40 \%$ in HFIP) (Table 1, entry IV), yet confirming the increasing helicity behaviour of oligomers with increasing $n$ as depicted with the "linear" line in Fig. 5.

The chain end effects introduced by alkyl groups on one end (mono-functional) e.g. OK(Z) and OK(TFA), or on both ends (bisfunctional) e.g. N-OK(Z) and N-OK(TFA), of the oligomer chains were examined by CD spectroscopy in HFIP and in TFE (see Table 1). Mono-functional oligomers, $\mathbf{O K}(\mathrm{Z})$ (Table 1, entry I) and OK(TFA) (Table 1, entry XIV) with equal chain length show higher $\alpha$-helicity in comparison to their bis-functional derivatives, N-OK(Z) (Table 1, entry II) and N-OK(TFA) (Table 1, entry $\mathrm{XV}$ ), suggesting that the alkyl end groups do not favour the helix formation. Furthermore, side chain effects stemming from amino-protecting groups, $\mathrm{Z}(\mathrm{Cbz})$ and TFA on conformational changes were also studied. We found that there was no distinctive difference in their $\alpha$-helicity values of $\mathbf{N}-\mathbf{O K}(\mathrm{Z})$ and $\mathbf{N}$ OK(TFA) oligomers induced by their side chains (Table 1 , entries II and XV respectively). Thus for instance, fractions f19 (with Z) (entry IX, $n=6,7$ ) and f2 (with TFA) (entry XVI, $n=6 \pm$ 1) possess similar $\alpha$-helicity values. However, as shown in Table 1 , there is a slight difference in $\alpha$-helicity values for the fractions with lower $n$, e.g. f5 (entry XIX, $n=3-4$ ) does not display $\alpha$ helicity, whereas f25 (entry XII, $n=4 \pm 1$ ) and f28 (entry XIII, $n$ $=3$ ) with similar ns show $12 \%$ helicity in TFE.

From Table 1 it can be also seen that TFE promotes helicity ${ }^{38}$ compared to HFIP. Fraction f12 of N-OK(Z) (entry V) displays $32 \% \alpha$-helicity in TFE whereas only $19 \% \alpha$-helicity is observed in HFIP. In the case of the fractions of N-OK(Z) measured in TFE (entries V-XIII) $\alpha$-helicity of more than $16 \%$ is observed with a number of repeating units higher than $8(n>8)$ starting from fractions $\mathrm{f} 19$ and f20 (entries IX and $\mathrm{X}$ respectively). TFE increases the stability and formation of the $\alpha$-helices over HFIP, explained by comparing polarities of both solvents, where TFE is more polar than HFIP. Pengo and Pasquato et al. ${ }^{39}$ have indicated a correlation between the polarities of different solvents and the equilibrium of the formation of $\alpha$-helix structures, proving that the more polar the solvent is e.g. TFE, the equilibrium shifts to the formation of $\alpha$-helical structures, whereas the less polar solvents promote the formation of $3_{10^{-}}$ helix structures. It has been stated that the hydroxyl group of TFE can bind to the carbonyl group in the peptide backbone via hydrogen bonding without disrupting the hydrogen bonding interactions between the carbonyls and the amines of the peptide forming the $\alpha$-helical structure. ${ }^{40}$

Influence of solvent composition and effects of number of repeating units of the peptide on the dynamics of the secondary structure formation of peptides and PEG-peptide diblock copolymers have reported that $\alpha$-helicity is increasing with increasing number of repeating units of a peptide chain and with addition of TFE. ${ }^{41,42}$

\section{Transmission electron microscopy (TEM) analyses}

There has been a number of reports on the visualization of the fibril formation of synthetic peptides at different physical and chemical conditions. ${ }^{43-45}$ More complex molecular assemblies of alkyl chain grafted PLLs with $n=60,130$ and 300 with varying degree of grafting have been analysed by TEM to observe the formation of vesicles at neutral $\mathrm{pH}^{46}$ Energy landscapes of peptide amphiphile nanofibers consisting of an alkyl tail and peptide unit with a propensity to form $\beta$-sheets have revealed that many products form monodisperse short fibres. ${ }^{47}$

In our study the TEM images of the fractions of N-OK(Z), f19 and $\mathrm{f} 28$, obtained after preparation in TFE $\left(c=0.2 \mathrm{mg} \mathrm{mL}^{-1}\right)$ are shown in Fig. 6 . The end groups of both $\mathrm{f} 19$ and $\mathrm{f} 28$ are functionalized with two $\mathrm{C} 11$ vinyl chains. The repeating unit $(n)$ of each sample is different; for $\mathrm{f} 19$, the repeating unit is $n \approx 7$, indicating that helix formation is already favoured, whereas for f28 $(n=3)$ the $\alpha$-helical turn could be only 1 , stabilized only with the help of TFE solvent. The TEM image of f19 $(n=7)$ shows a dense mesh of large fibrils (see Fig. 6a), while stacks of fibrillar bundles are formed by f28 $(n=3)$ (see Fig. 6b).

As shown in Fig. 6, we chose fractions f19 and f28 to demonstrate the effect of number of repeating units $(n)$, specifically in the case of very low $D$ values, on the formation of fibrils due to their secondary structural interactions. We did also investigate fibril formation of various other samples (see Fig. 36S-40S†), where solvent of choice and the fraction between helical chain lengths have been probed. In addition to the data shown in Fig. 6 and the CD results discussed above (Table 1, Fig. 4 and 5), a higher propensity to form fibrils is accompanied with a higher degree to form alpha helices, suggesting the

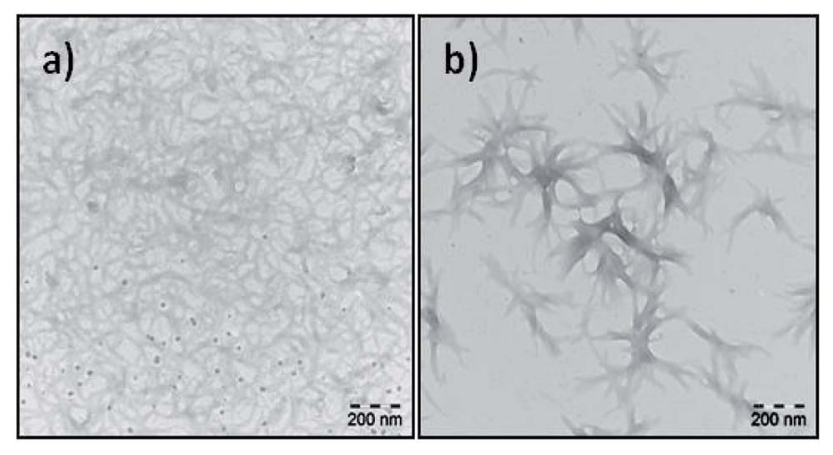

Fig. 6 TEM images of $f 19$ (a) and f28 (b) in TFE. 
formed to be promoted by the latter. We propose that increasing $\alpha$-helicity is crucial to form fibrils owing to their improved packing accompanied by a more precise conformational identity of the peptide with the lower entropy.

\section{Conclusions}

In this work, we successfully synthesized mono- and bisfunctionalized lysine oligomers with two different protecting groups (Z) and (TFA). We separated bis-functional N-OK(Z) and N-OK(TFA) into fractions by using preparative GPC in DMF to obtain lower polydispersity values of the low molecular weight oligomers. All synthesized oligomers and selectively chosen fractionated samples were analysed by ${ }^{1} \mathrm{H}-\mathrm{NMR}$, analytical GPC and MALDI-ToF MS. The secondary structural investigations were conducted with the help of CD spectroscopy in HFIP and TFE. From our results we conclude that TFE stabilizes helicity better than HFIP. Additionally, as shown in Table 1, we have observed that the functionalization of both end groups of the peptide decreases the stability of the $\alpha$-helicity for the cases of $\mathrm{O}-\mathrm{K}(\mathrm{Z} / \mathrm{TFA})$ and N-OK(Z/TFA). The fractions of N-OK(Z) and $\mathbf{N}-$ OK(TFA) were selectively investigated by CD spectroscopy in HFIP and in TFE, aiming to focus on the effect of the chain length of the peptide on the formation of $\alpha$-helices. We can prove that the number of repeating units of the oligomers significantly affects the ability to form helical structure, showing that higher $n$ values result in an increased amount of $\alpha$ helicity as depicted with the linear line in Fig. 5. Moreover, from TEM images we can confirm that in TFE larger fibrils form a dense mesh, when $n$ is larger than 3 (f19), whereas oligomers with a small number of repeating unit $(n=3)$ (f28) form small stacks of fibrillar bundles.

The so obtained data allow us to quantify the amount of secondary structure ( $\alpha$-helicity) present within the functionalized oligo-L-lysines of precise chain length on basis of eqn (1). It is crucial to understand peptide assemblies in view of the initial conformational interactions and their secondary structure formation, hence we here for the first time represent a rational approach to engineer future fibril forming systems, based on oligomeric-L-lysines with very low $D$ values $(D<1.07)$. Last but not least, it should be also emphasized that such artificial fibril forming assemblies hold great potential applications as inhibitors for amyloidosis of complex proteins e.g. A $\beta$. The influence of lipidic alkyl end groups and chain length of peptide unit on the folding behaviours of peptides within a hybrid polymer can thus be quantified, prospectively reported in future work.

\section{Conflicts of interest}

There are no conflicts to declare.

\section{Acknowledgements}

We thank the grant Project A03 nr. 189853844-TRR 102 (Polymers under multiple constraints) for financial support from the German Research Foundation (DFG) via the research centre SFB/TRR 102 (Project A3 and A12). We also thank a grant from the "Leistungszentrum Chemie und Biosystemtechnik des Landes Sachsen-Anhalt" for financial support, internal project S1 (Binder). I would like to thank Prof. Hauke Lilie from the Institute of Biochemistry and Biotechnology, Martin Luther University Halle-Wittenberg for allowing me to work with the CD spectroscopy instrument and also Dr Gerd Hause from Biocentre, Martin Luther University Halle-Wittenberg for his contributions to our TEM measurements.

\section{Notes and references}

1 H. Lu, J. Wang, Z. Song, L. Yin, Y. Zhang, H. Tang, C. Tu, Y. Lin and J. Cheng, Chem. Commun., 2014, 50, 139-155.

2 J. C. Johnson and L. T. J. Korley, Soft Matter, 2012, 8, 1143111442 .

3 I. W. Hamley, Angew. Chem., Int. Ed., 2007, 46, 8128-8147.

4 B. Wang, E. H. Pilkington, Y. Sun, T. P. Davis, P. C. Ke and F. Ding, Environ. Sci.: Nano, 2017, 4, 1772-1783.

5 S. Williams, T. P. Causgrove, R. Gilmanshin, K. S. Fang, R. H. Callender, W. H. Woodruff and R. B. Dyer, Biochemistry, 1996, 35, 691-697.

6 K. Pagel, S. C. Wagner, K. Samedov, H. von Berlepsch, C. Böttcher and B. Koksch, J. Am. Chem. Soc., 2006, 128, 2196-2197.

7 J. Li, X. Du, S. Hashim, A. Shy and B. Xu, J. Am. Chem. Soc., 2017, 139, 71-74.

8 I. W. Hamley, Chem. Rev., 2012, 112, 5147-5192.

9 I. W. Hamley and V. Castelletto, Bioconjugate Chem., 2017, 28, 731-739.

10 G. D. Fasman, Biopolymers, 1987, 26, S59-S79.

11 V. Stanić, Y. Arntz, D. Richard, C. Affolter, I. Nguyen, C. Crucifix, P. Schultz, C. Baehr, B. Frisch and J. Ogier, Biomacromolecules, 2008, 9, 2048-2055.

12 V. Incani, X. Lin, A. Lavasanifar and H. Uludağ, ACS Appl. Mater. Interfaces, 2009, 1, 841-848.

13 M. Chittchang, H. H. Alur, A. K. Mitra and T. P. Johnston, J. Pharm. Pharmacol., 2002, 54, 315-323.

14 M. Chittchang, N. Salamat-Miller, H. H. Alur, D. G. V. Velde, A. K. Mitra and T. P. Johnston, J. Pharm. Pharmacol., 2002, 54, 1497-1505.

15 Y.-C. Huang, M. Arham and J.-S. Jan, Soft Matter, 2011, 7, 3975-3983.

16 S. Sinha, D. H. J. Lopes, Z. Du, E. S. Pang, A. Shanmugam, A. Lomakin, P. Talbiersky, A. Tennstaedt, K. McDaniel, R. Bakshi, P.-Y. Kuo, M. Ehrmann, G. B. Benedek, J. A. Loo, F.-G. Klärner, T. Schrader, C. Wang and G. Bitan, J. Am. Chem. Soc., 2011, 133, 16958-16969.

17 E. Katchalski, I. Grossfeld and M. Frankel, J. Am. Chem. Soc., 1948, 70, 2094-2101.

18 H. Yakel Jr, Acta Crystallogr., 1953, 6, 724-727.

19 G. D. Fasman, M. Idelson and E. R. Blout, J. Am. Chem. Soc., 1961, 83, 709-712.

20 B. Davidson and G. D. Fasman, Biochemistry, 1967, 6, 16161629.

21 A. Mirtič and J. Grdadolnik, Biophys. Chem., 2013, 175-176, 47-53. 
22 D. Huesmann, A. Birke, K. Klinker, S. Türk, H. J. Räder and M. Barz, Macromolecules, 2014, 47, 928-936.

23 V. Castelletto, A. Kaur, R. M. Kowalczyk, I. W. Hamley, M. Reza and J. Ruokolainen, Biomacromolecules, 2017, 18, 2013-2023.

24 P. A. Korevaar, C. J. Newcomb, E. W. Meijer and S. I. Stupp, J. Am. Chem. Soc., 2014, 136, 8540-8543.

25 M. P. Hendricks, K. Sato, L. C. Palmer and S. I. Stupp, Acc. Chem. Res., 2017, 50, 2440-2448.

26 G. J. M. Habraken, M. Peeters, C. H. J. T. Dietz, C. E. Koning and A. Heise, Polym. Chem., 2010, 1, 514-524.

27 G. J. M. Habraken, K. H. R. M. Wilsens, C. E. Koning and A. Heise, Polym. Chem., 2011, 2, 1322-1330.

28 A. C. Farthing and R. J. W. Reynolds, Nature, 1950, 165, 647.

29 C. Deng, J. Wu, R. Cheng, F. Meng, H.-A. Klok and Z. Zhong, Prog. Polym. Sci., 2014, 39, 330-364.

$30 \mathrm{H}$. H. James, in Ring-Opening Polymerization, American Chemical Society, 1985, ch. 5, vol. 286, pp. 67-85.

$31 \mathrm{~W}$. Zhao, Y. Gnanou and N. Hadjichristidis, Biomacromolecules, 2015, 16, 1352-1357.

32 J. Zou, J. Fan, X. He, S. Zhang, H. Wang and K. L. Wooley, Macromolecules, 2013, 46, 4223-4226.

33 W. Vayaboury, O. Giani, H. Cottet, A. Deratani and F. Schué, Macromol. Rapid Commun., 2004, 25, 1221-1224.

34 W. N. E. Van Dijk-Wolthuis, L. van de Water, P. van de Wetering, M. J. Van Steenbergen, J. J. Kettenes-van den Bosch, W. J. W. Schuyl and W. E. Hennink, Macromol. Chem. Phys., 1997, 198, 3893-3906.
35 T. Aliferis, H. Iatrou and N. Hadjichristidis, Biomacromolecules, 2004, 5, 1653-1656.

36 N. J. Greenfield, Nat. Protoc., 2007, 1, 2876-2890.

37 K.-S. Krannig, J. Sun and H. Schlaad, Biomacromolecules, 2014, 15, 978-984.

38 A. Kentsis and T. R. Sosnick, Biochemistry, 1998, 37, 1461314622.

39 P. Pengo, L. Pasquato, S. Moro, A. Brigo, F. Fogolari, Q. B. Broxterman, B. Kaptein and P. Scrimin, Angew. Chem., 2003, 115, 3510-3514.

40 R. Rajan and P. Balaram, Int. J. Pept. Protein Res., 1996, 48, 328-336.

41 M. Pechar, P. Kopečková, L. Joss and J. Kopeček, Macromol. Biosci., 2002, 2, 199-206.

42 G. W. M. Vandermeulen, C. Tziatzios and H.-A. Klok, Macromolecules, 2003, 36, 4107-4114.

43 D. Punihaole, R. S. Jakubek, R. J. Workman, L. E. Marbella, P. Campbell, J. D. Madura and S. A. Asher, J. Phys. Chem. B, 2017, 121, 5953-5967.

44 I. W. Hamley, A. Dehsorkhi and V. Castelletto, Langmuir, 2013, 29, 5050-5059.

45 M. J. Krysmann, V. Castelletto and I. W. Hamley, Soft Matter, 2007, 3, 1401-1406.

46 B.-Y. Chen, Y.-C. Huang and J.-S. Jan, $R S C A d v ., 2015,5$, 22783-22791.

47 F. Tantakitti, J. Boekhoven, X. Wang, R. V. Kazantsev, T. Yu, J. Li, E. Zhuang, R. Zandi, J. H. Ortony, C. J. Newcomb, L. C. Palmer, G. S. Shekhawat, M. O. de la Cruz, G. C. Schatz and S. I. Stupp, Nat. Mater., 2016, 15, 469. 